\title{
Study the Effect of Cooling Rate on Fatigue Strength and Fatigue Life of Heated Carbon Steel Bars
}

\author{
Ali S. Yasir ${ }^{1}$ \\ ${ }^{1}$ Mechanical Engineering Department, University of Kufa, Iraq \\ Correspondence: Ali S. Yasir, Mechanical Engineering Department, University of Kufa, Iraq. E-mail: \\ alis.alathari@uokufa.edu.iq, ali_sadiq76@yahoo.com
}

Received: March 27, 2013

Accepted: May 23, 2013 Online Published: July 10, 2013

doi:10.5539/mer.v3n2p1

URL: http://dx.doi.org/10.5539/mer.v3n2p1

\begin{abstract}
The fatigue failure is the reason of $(90 \%)$ of mechanical failures. This work tries improving the fatigue strength and increasing the fatigue life for steel bars that used in concrete reinforcing. Tensile test were done to find the mechanical properties of steel bar. The heating over critical temperature $\left(\mathrm{AC}_{3}\right)$ and cooling by different cooling rates were done for steel bars, and tested this samples by tensile and fatigue tests. The tensile test results show increasing in yield and tensile strength for sample that cooled by oil (medium cooling rate).The fatigue test results show increasing in the fatigue life for samples that cooled by oil.
\end{abstract}

Keywords: fatigue strength, fatigue life, cooling rate, tensile strength, carbon steel

\begin{tabular}{ll}
\multicolumn{2}{l}{ Nomenclature } \\
$\sigma_{\mathrm{f}}$ & Fatigue failure $\left(\mathrm{N} / \mathrm{mm}^{2}\right)$ \\
$\sigma_{\mathrm{t}}$ & Tensile Strength $\left(\mathrm{N} / \mathrm{mm}^{2}\right)$ \\
$\sigma_{\mathrm{m}}$ & Mean Stress $\left(\mathrm{N} / \mathrm{mm}^{2}\right)$ \\
$\sigma_{\mathrm{r}}$ & Range stress $\left(\mathrm{N} / \mathrm{mm}^{2}\right)$ \\
$\sigma_{\mathrm{a}}$ & Amplitude Stress $\left(\mathrm{N} / \mathrm{mm}^{2}\right)$ \\
$\mathrm{R}$ & Stress Ratio \\
$\sigma_{\mathrm{b}}$ & Bending Stress $\left(\mathrm{N} / \mathrm{mm}^{2}\right)$ \\
$\mathrm{M}$ & Bending Moment $(\mathrm{N} . \mathrm{m})$ \\
$\mathrm{d}$ & Sample diameter $(\mathrm{m})$ \\
$\mathrm{P}$ & Bending Load $(\mathrm{N})$ \\
$\mathrm{L}$ & Length of Sample (m) \\
$\mathrm{K}_{\mathrm{f}}$ & Fatigue stress concentration factor \\
$\mathrm{q}$ & Notch sensitivity \\
$\mathrm{K}_{\mathrm{t}}$ & Stress concentration factor
\end{tabular}

\section{Introduction}

Fatigue is referred to the degradation of mechanical properties leading to failure of a material or component under cyclic loading as shown in Figure 1. According to ASTM the standard definition of fatigue is the process of progressive localized permanent structural change occurring in material subjected to conditions that produce fluctuating stresses and strains at some point or points and that may culminate in crack or complete fracture after sufficient number of fluctuations (Andresen et al., 1997). 


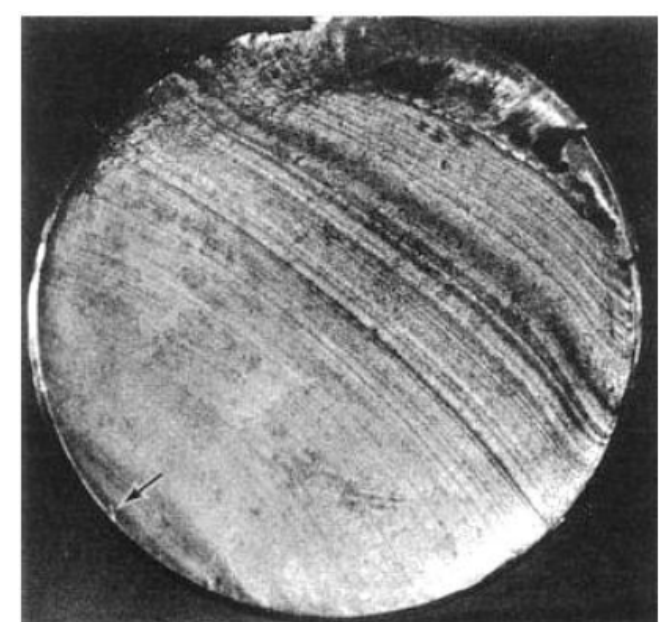

Figure 1. Shape of fatigue failure of steel shaft (Andresen et al., 1997)

Fatigue strength of materials is often defined as the maximum stress amplitude without failure after given number of cycles.

It is estimated that about $(90 \%)$ of service failure of metallic components resulted from fatigue. However, it is very time and money consuming to perform fatigue tests. Therefore, many attempts have been made to determine the fatigue strength in cost-effective way relating fatigue strength to other mechanical properties, such as yield strength, tensile strength, hardness (Pang et al., 2013; Murakami et al., 2002).

Engineers and scientists have proposed many formulas to describe the relations between fatigue strength and other mechanical properties (Murakami et al., 2002; Bathias et al., 2005; Lee et al., 2005).

In 1870 s, Wöhler, one of the German pioneers in the fatigue field, found that the ratio of fatigue strength $\left(\sigma_{\mathrm{f}}\right)$ to tensile strength $\left(\sigma_{\mathrm{t}}\right)$ for ferrous metals followed a simple proportional relation as below:

$$
\sigma_{f}^{\prime}=(0.4-0.5) \sigma_{t}^{\prime}
$$

Based on the numerous data of fatigue strength and tensile strength available for steel, aluminum, and copper alloys (Lee et al., 2005).

Fleck, study and determine the fatigue crack growth rate and crack closure response of steel under service loading at gas storage vessel. Crack propagation rates are found to be independent of specimen thickness. Crack growth is successfully predicted by linear summation using Paris law (Fleck et al., 1984).

Greger, study the deformation on low cycles fatigue of steel (AISI 316) by using (ECAP) technology and find the mechanical properties of steel samples by this technique, the fine grain sample of steel show shorter fatigue service life than the initial state samples (Kander, 2008).

Tilly, study the fatigue life and fatigue strength of reinforcing steel bar by using axial and bending fatigue tests and find that the endurance of steel bar influenced by type of steel, geometry, size of bars, and nature of cyclic loading and set the fatigue life of reinforced steel bar as shown in Figure 2 (Tilly,1979). 


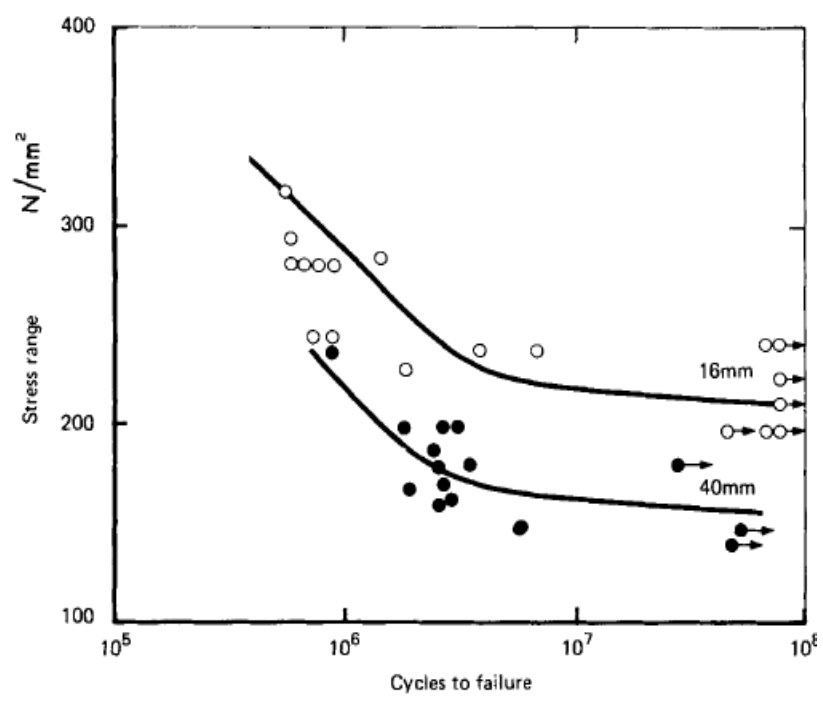

Figure 2. S-N diagram for steel (Tilly, 1979)

Jeff Brown, carried out the comprehensive experimental study to examine the low-cycle fatigue of ordinary reinforcing steel bars, the results showed that the fatigue life influenced by the diameter of bar and the geometry of rolled on deformation (Brown et al., 2004).

Rami Hawileh et al, study the behavior of mild steel bars under low cycle fatigue and using the non-linear finite element analysis of 3-D model to show the behavior of mild steel under fatigue loading (Hwileh \& Rahman, 2010).

\section{Experimental Materials and Work}

The steel bar samples that used in this work had the chemical composition shown in Table 1.

Table 1. Chemical composition of steel bar

\begin{tabular}{ccccccccc}
\hline Composition & $\mathrm{C}$ & $\mathrm{Cr}$ & $\mathrm{Ni}$ & $\mathrm{Mn}$ & $\mathrm{Si}$ & $\mathrm{P}$ & $\mathrm{S}$ & $\mathrm{Fe}$ \\
\hline $\mathrm{Wt} \%$ & 27 & 0.3 & 0.3 & 1.6 & 0.55 & 0.04 & 0.04 & Balance \\
\hline
\end{tabular}

\subsection{Tensile Test}

The tensile test were done according to specification (DIN 50125) to set the properties of steel sample like (young modulus, yield strength, and ultimate strength) by used the tensile test machine that shown in figure (3) and the sample dimension for tensile test shown in Figure 4.

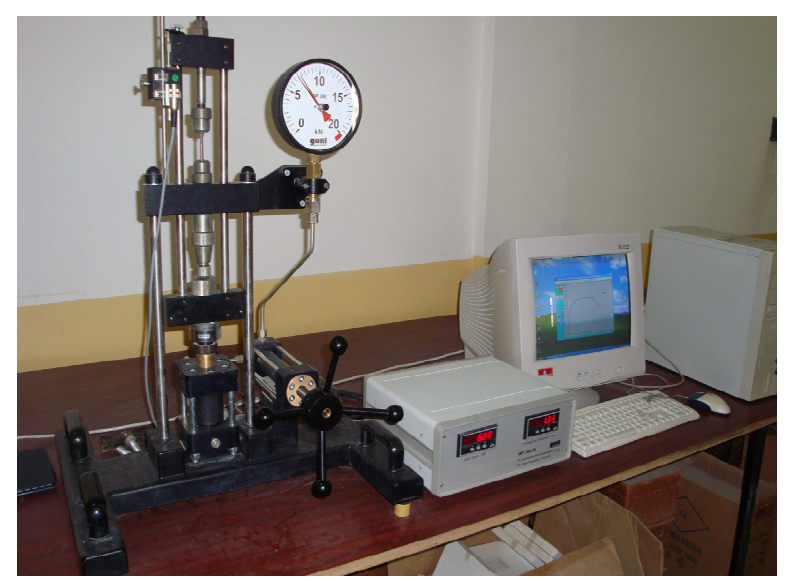

Figure 3. Tensile test machine 


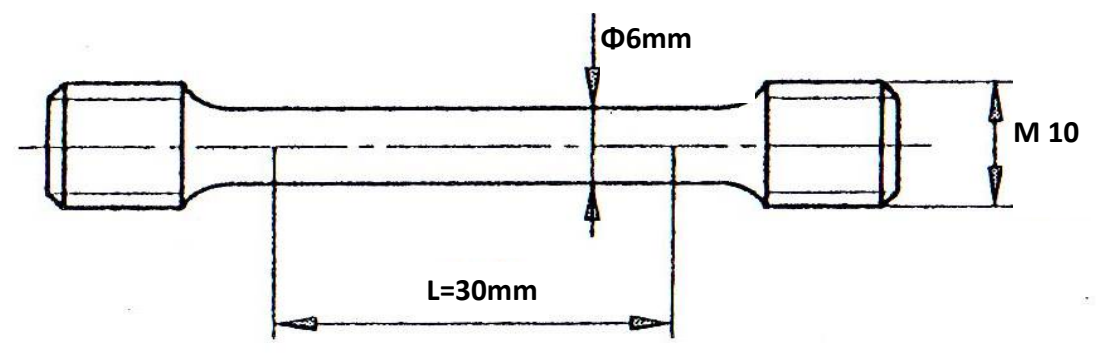

Figure 4. Tensile test sample

\subsection{Heating Process and Cooling}

The heating process for samples done by used the electrical furnace; the samples were heated to temperature of $\left(930{ }^{\circ} \mathrm{C}\right)$ to ensure the phase transformation then the samples cooled by using different types of cooling media as: (Arai, 1997; Yuce, 2007; Herring, 2007)

1) Very slow cooling (inside furnace):- The very slow cooling will provide the time to austenite microstructure to transform to pearlite structure that had good strength but low hardness.

2) Slow cooling (still air):- The advantages of using air are that distortion is negligible and that the steel can easily straightened during cooling process.

3) Medium cooling (by oil):- The medium cooling reduced likelihood of cracking. Problems associated with quenchants include water contamination, smoke and fire hazards.

4) Fast cooling (by water):- water is good quenching medium. It is cheap, readily available, easily stored nontoxic nonflammable smokeless and easy to filer and pump but with water quench the formation of bubbles may cause soft spots in the metal. Still other problems with water quench include its oxidizing nature, its corrosivity and the tendency to excessive distortion and cracking

5) High speed cooling by brine (salt+water):- Brine is a more severe quench medium than water. Unfortunately, it tends to accelerate corrosion problems unless completely removed.

Cooling media and cooling rates had shown in Table 2.

Table 2. Cooling rate for different cooling media (Yuci, 2007)

\begin{tabular}{cccccc}
\hline Cooling Media & Inside furnace & Still Air & Oil & Water & Water + Salt \\
\hline Cooling Rate $\left(\mathrm{C}^{\mathrm{o}} / \mathrm{sec}\right)$ & 0.011 & 1.2 & 17 & 77 & 150 \\
\hline
\end{tabular}

\subsection{Fatigue Test}

The fatigue test for steel samples done according to specification (ASTM E467) by applied the bending load at the end of cantilever rotating sample with speed of $(2000 \mathrm{rpm})$ of fatigue testing machine that shown in figure (5), and the sample of test prepared to final dimensions as shown in Figure 6. The bending load applied at the end of sample as $(95 \mathrm{~N}, 115 \mathrm{~N}, 125 \mathrm{~N}, 160 \mathrm{~N}$, and $200 \mathrm{~N})$. 


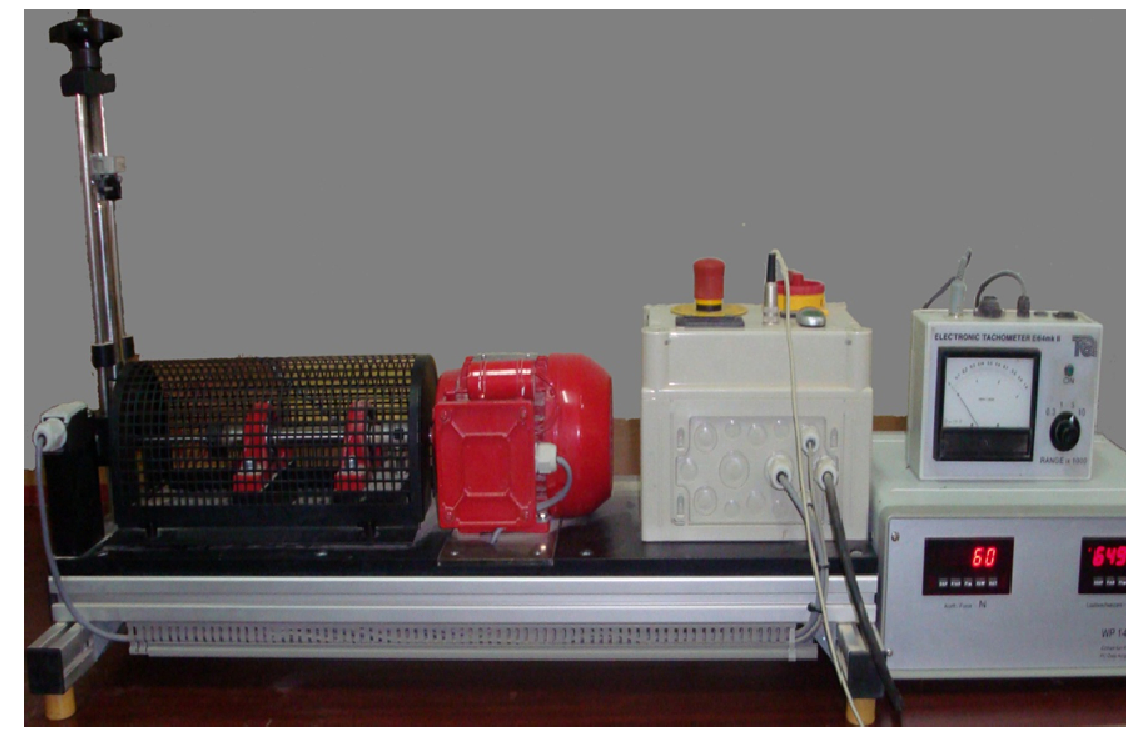

Figure 5. Fatigue testing machine

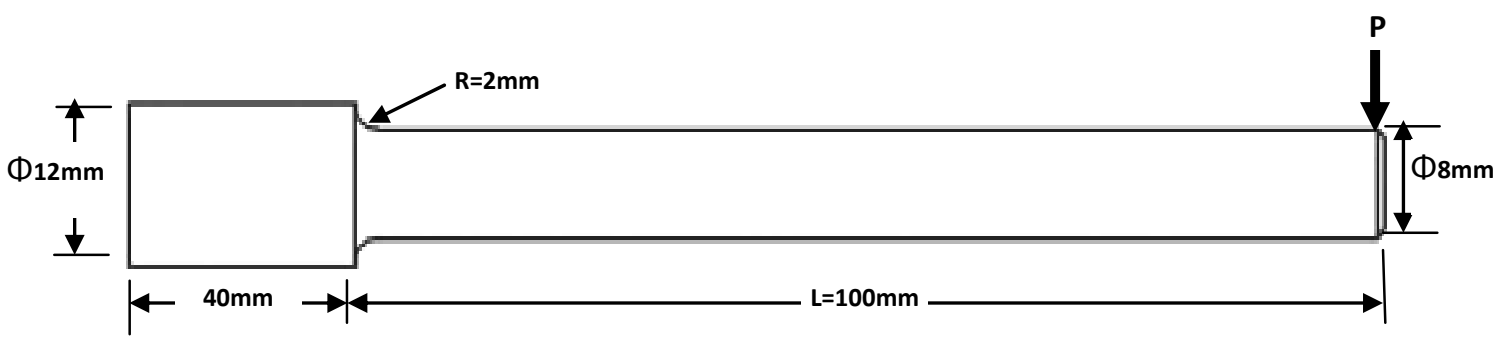

Figure 6. Fatigue test sample

\section{Calculations}

In most laboratory fatigue testing, the specimen is loaded so that stress it is cycled either between a maximum and minimum tensile stress or between a maximum tensile stress and specific level of compressive stress. The letter of the two, considered a negative tensile stress, are given an algebraic minus sign and called the minimum stress. The mean stress $\left(\sigma_{\mathrm{m}}\right)$ is algebraic average of maximum stress and minimum stress in one cycle: (Boardman, 1990)

$$
\sigma_{m}=\frac{\sigma_{\text {max }}+\sigma_{\text {min }}}{2}
$$

The range of stress $\left(\sigma_{\mathrm{r}}\right)$ is algebraic difference between maximum stress and minimum stress in one cycle:

$$
\sigma_{r}=\sigma_{\text {max }}-\sigma_{\text {min }}
$$

The stress amplitude $\left(\sigma_{\mathrm{a}}\right)$ is one-half the range of stress in one cycle:

$$
\sigma_{a}=\frac{\sigma_{r}}{2}=\frac{\sigma_{\max }+\sigma_{\min }}{2}
$$

The stress ratio is the algebraic ratio of two specific stress values in stress cycle:

$$
R=\frac{\sigma_{\text {min }}}{\sigma_{\max }}
$$

The nominal stress in fully reversed bending loading test is: 


$$
\begin{gathered}
R=\frac{\sigma_{\text {min }}}{\sigma_{\text {max }}} \\
M=P^{*} L
\end{gathered}
$$

The fatigue fracture of structural details subjected to cyclic loads mostly occurs at a critical cross section with stress concentration. The stress concentration factor $\left(\mathrm{K}_{\mathrm{t}}\right)$ for stepped shaft depend on the dimension of stepped sample as shown in Figure 7 (Pilkey, 1997).

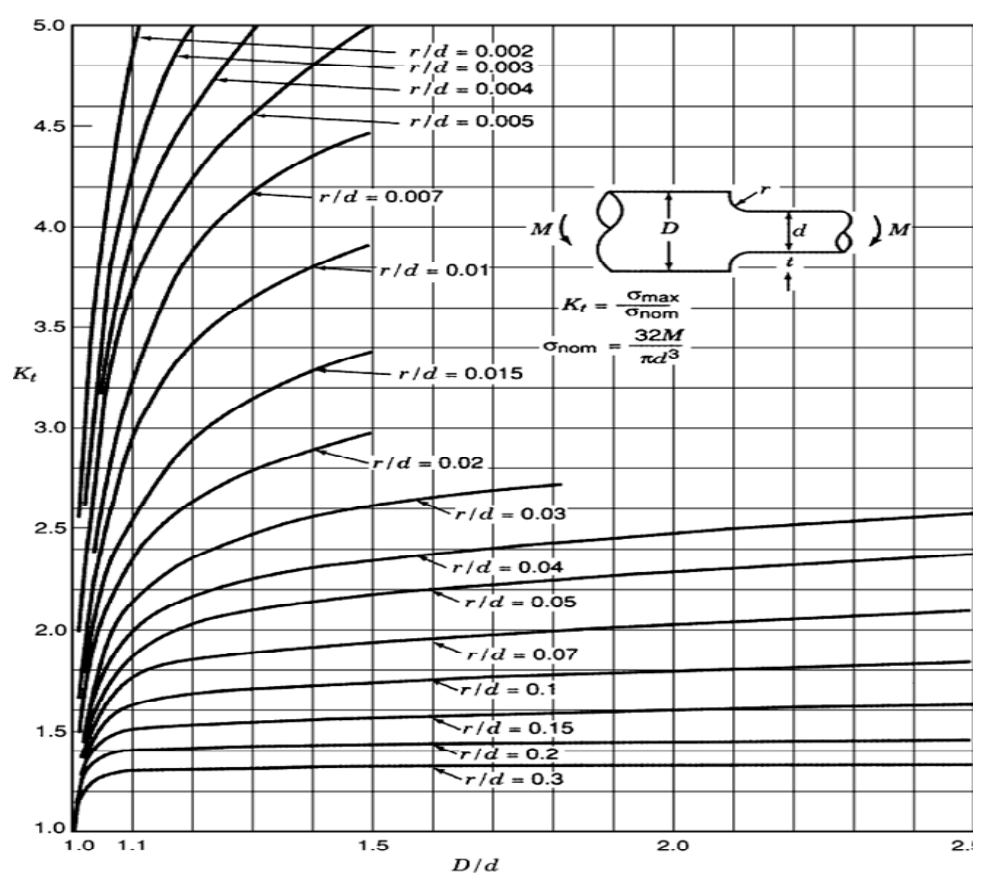

Figure 7. Stress concentration factor curves (Pilkey, 1997)

The fatigue stress concentration factor $\left(\mathrm{K}_{\mathrm{f}}\right)$ depend on the value of stress concentration $\left(\mathrm{K}_{\mathrm{t}}\right)$ and the notch sensitivity factor (q), that can found from notch sensitivity curve as shown in Figure 8.

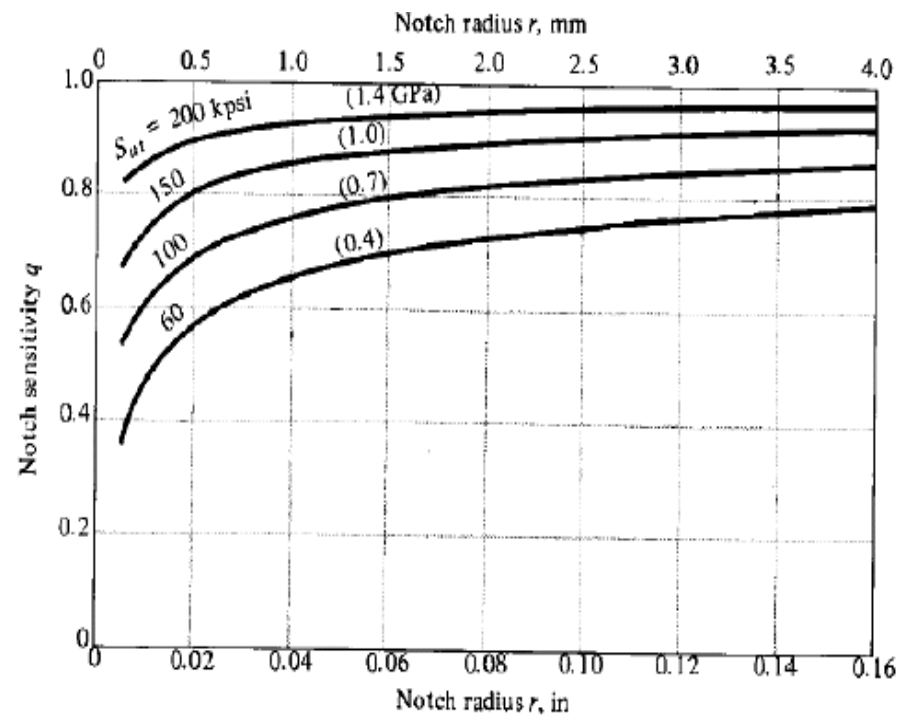

Figure 8. Notch sensitivity (q) values for diffent materials (Kharagpour, 2010) 
The value of fatigue stress concentration according to Equation (8).

$$
K_{f}=1+q\left(K_{t}-1\right)
$$

So the value of actual fatigue stress equal to $=$ Nominal bending stress $*$ Fatigue stress concentration factor.

$$
\sigma_{f_{a c t}}=\sigma_{b}^{*} K_{f}
$$

\section{Results and Discussion}

\subsection{Tensile Test}

Figure 9 shows the stress-strain diagram for steel bar at original state, from this curve the yield strength was ( 320 $\mathrm{MPa})$ and ultimate strength $(465 \mathrm{MPa})$ and that refer to the steel bar is mild steel material that had good ductility properties.

Figure 10 shows the relation between the cooling rate after heating and the yield strength for steel bars, while Figure 11 shows the relation between the cooling rate after heating and the ultimate tensile strength of steel bars. These figures show that the better yield and ultimate tensile strength were for samples that cooled by oil at cooling speed $(17 \mathrm{C} / \mathrm{sec})$, these refer to that the sample cooled with oil will have the microstructure of binite phase that had good tensile properties and good toughness.

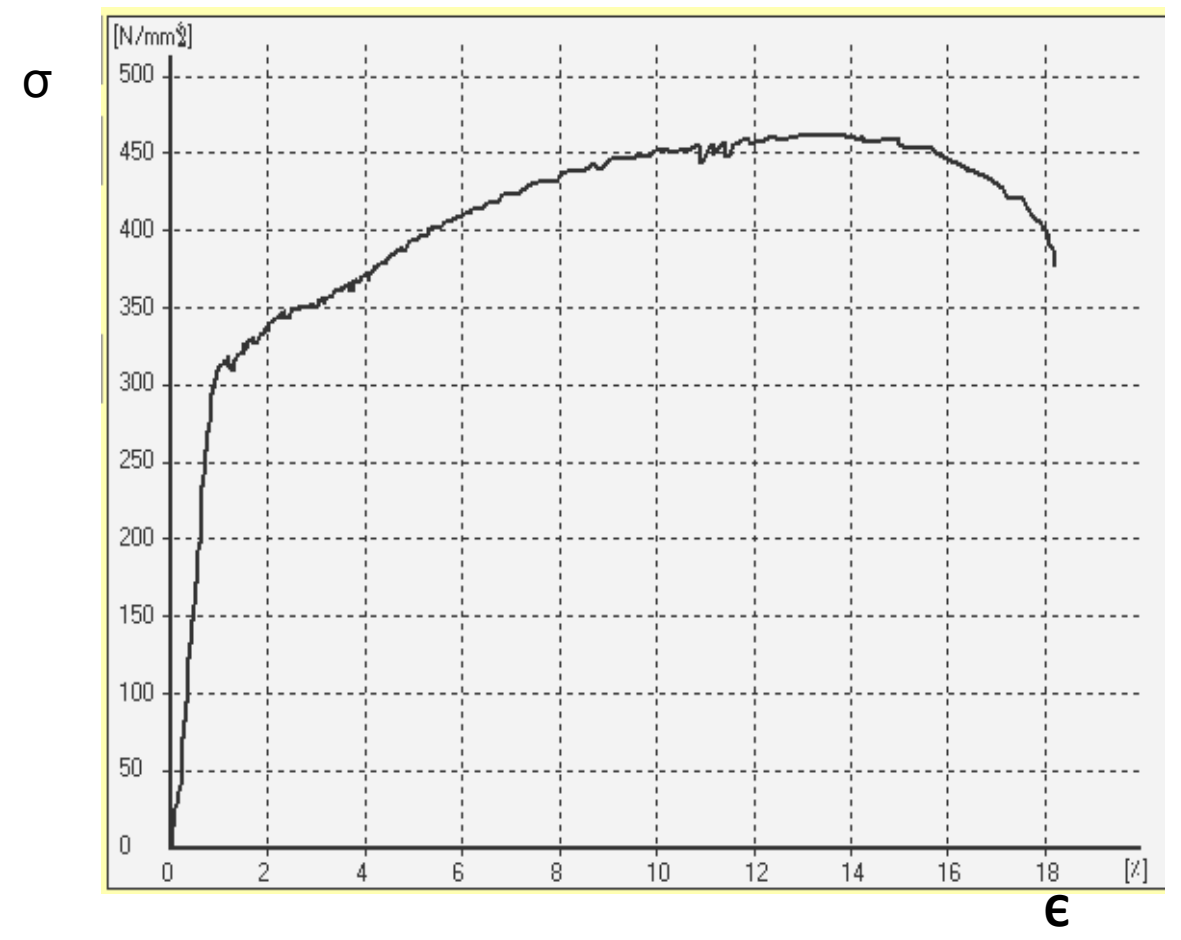

Figure 9. Stress-strain diagram for steel bar 


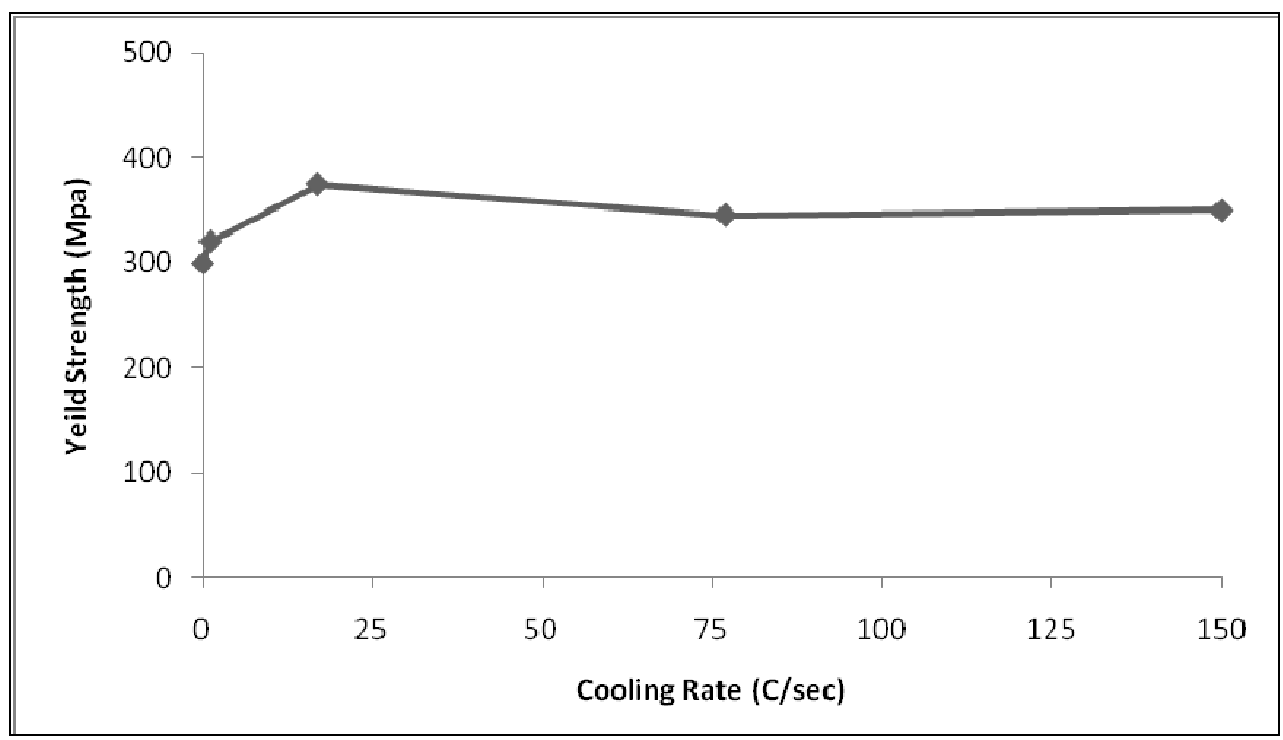

Figure 10. Relation between the cooling rate and yield strength of steel bar

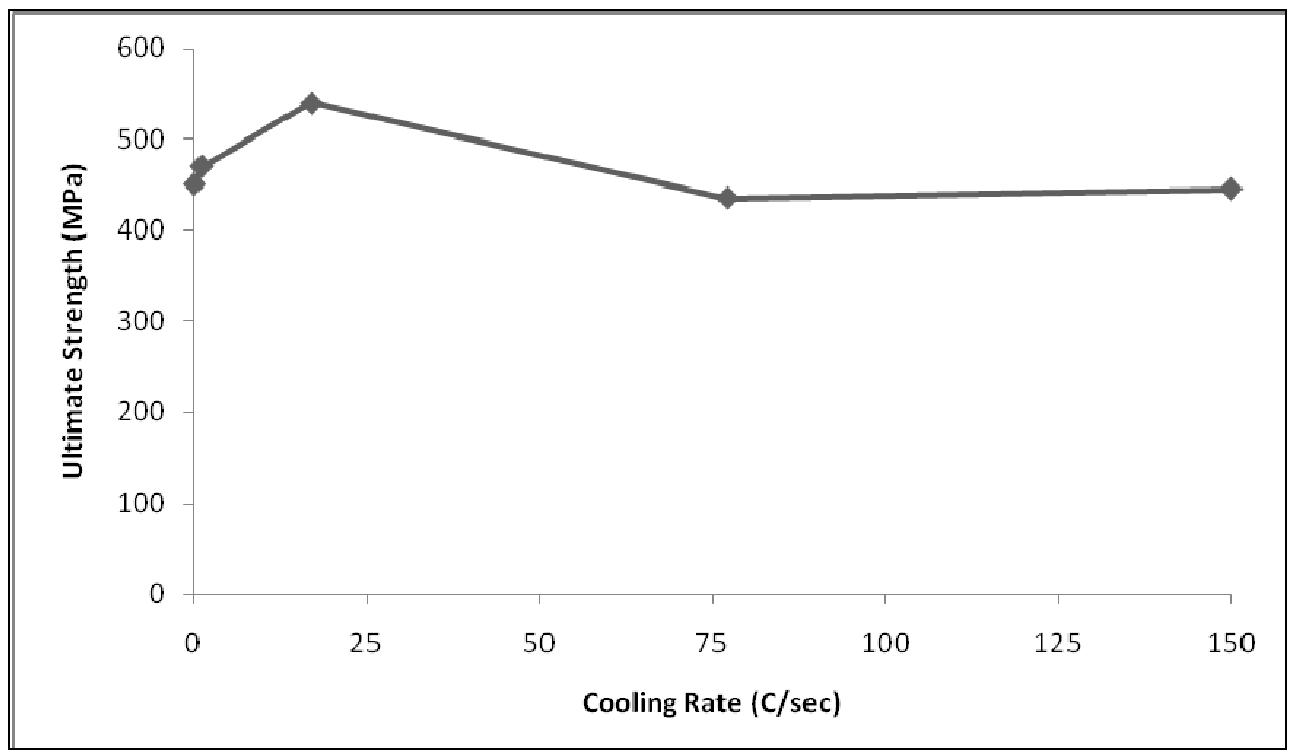

Figure 11. Relation between the cooling rate and ultimate tensile strength of steel bar

\subsection{Fatigue Test}

Figures $(12,13,14,15,16$, and 17) show the (S-N) diagram for steel bar without heating and cooling, heating and cooling inside furnace $(\mathrm{C} . \mathrm{R}=0.11 \mathrm{Co} / \mathrm{sec})$, heating and cooling by air $(\mathrm{C} . \mathrm{R}=1.2 \mathrm{Co} / \mathrm{sec})$, heating and cooling by oil $(C . R=17 \mathrm{Co} / \mathrm{sec})$, heating and cooling by water $(C . R=7711 \mathrm{Co} / \mathrm{sec})$, and heating and cooling in brine $(C . R=150 \mathrm{Co} / \mathrm{sec})$.Form these figures can notice the behavior of steel under fully reversed cyclic loading $(R=-1)$, was better for samples that heated and cooling by oil $(C . R=17 \mathrm{Co} / \mathrm{sec})$, while the endurance limit was constant were the better value of fatigue life was for samples cooled by oil that had longer fatigue life than other samples that cooled by other type of cooling media. The increase if fatigue life (number of cycles) happened as the cooling by oil gave binite microstructure for steel that had good toughness and harder to crack initiation on the sample surface that may growth to cause fatigue failure. The fatigue life for oil cooling samples increase (10 times) than the sample in original state, for water cooling samples fatigue life increased about (1.85 times), while it decrease for inside furnace, still air, brine cooling samples as shown in Figure 18. 


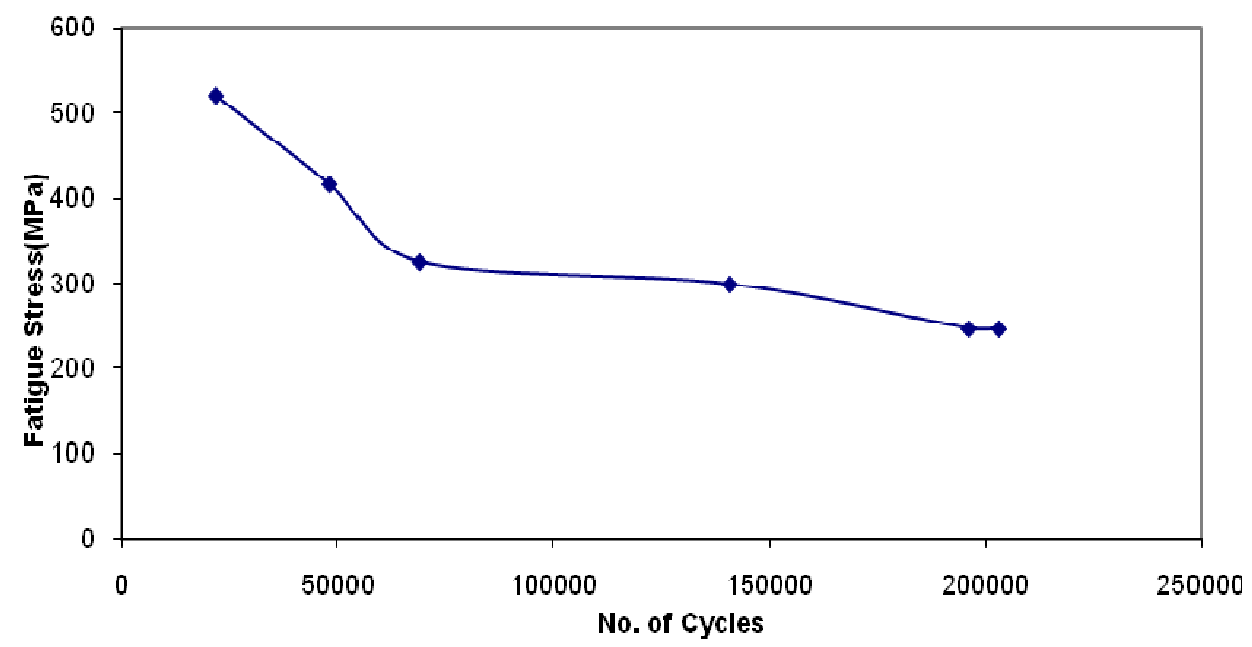

Figure 12. S-N diagram for steel bar without heating and cooling

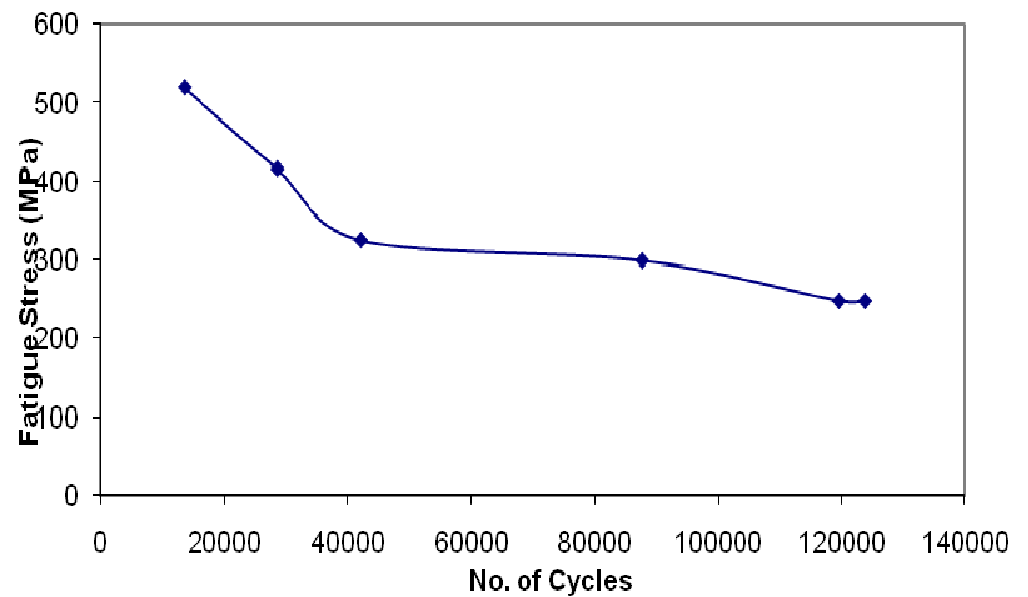

Figure 13. S-N diagram for steel bar heating and cooling inside furnance $\left(\mathrm{C} . \mathrm{R}=0.011{ }^{\circ} \mathrm{C} / \mathrm{sec}\right)$

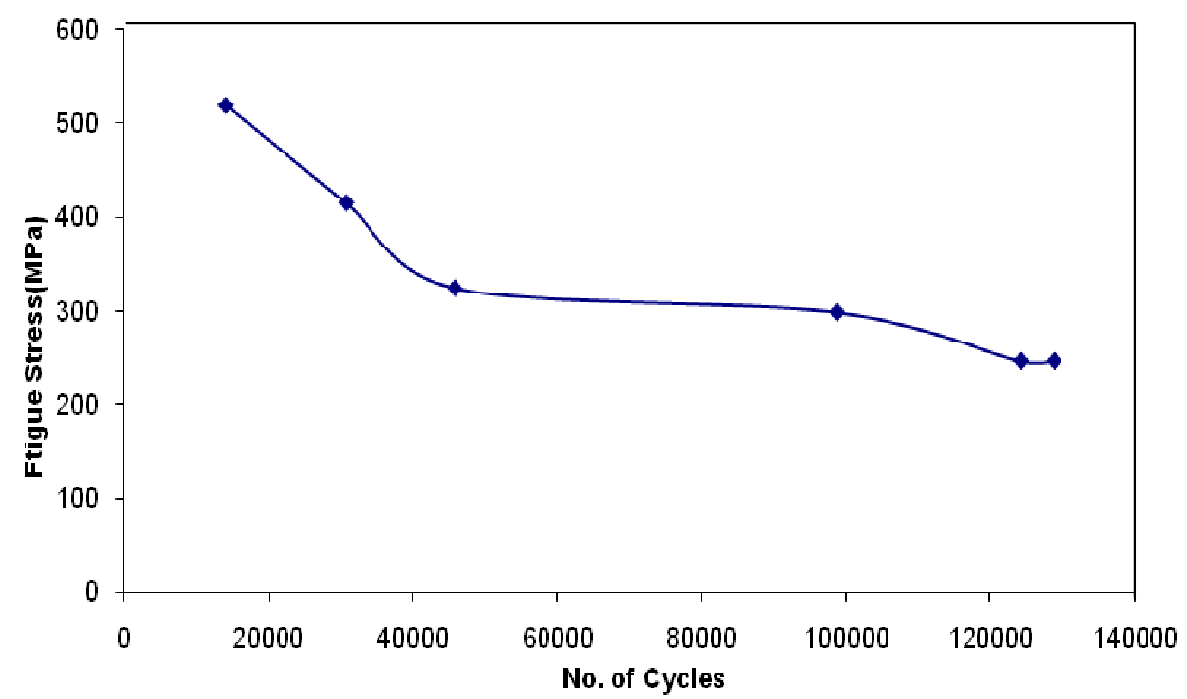

Figure 14. S-N diagram for steel bar heating and cooling by still air 


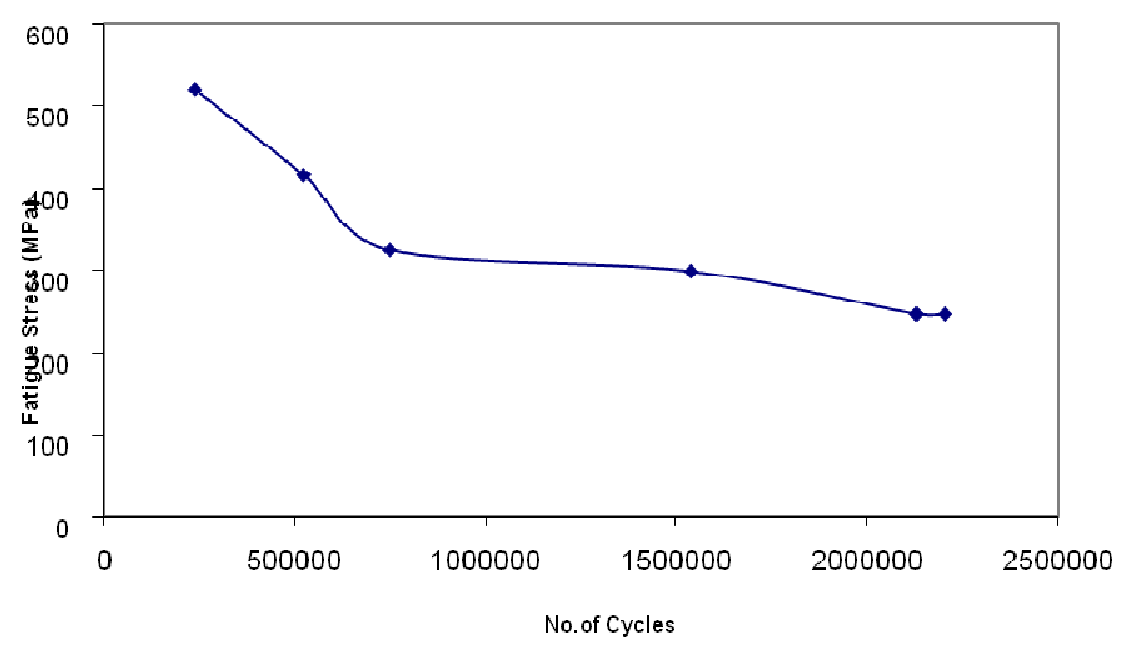

Figure 15. S-N diagram for steel bar heating and cooling by oil $\left(\mathrm{C} \cdot \mathrm{R}=17^{\circ} \mathrm{C} / \mathrm{sec}\right)$

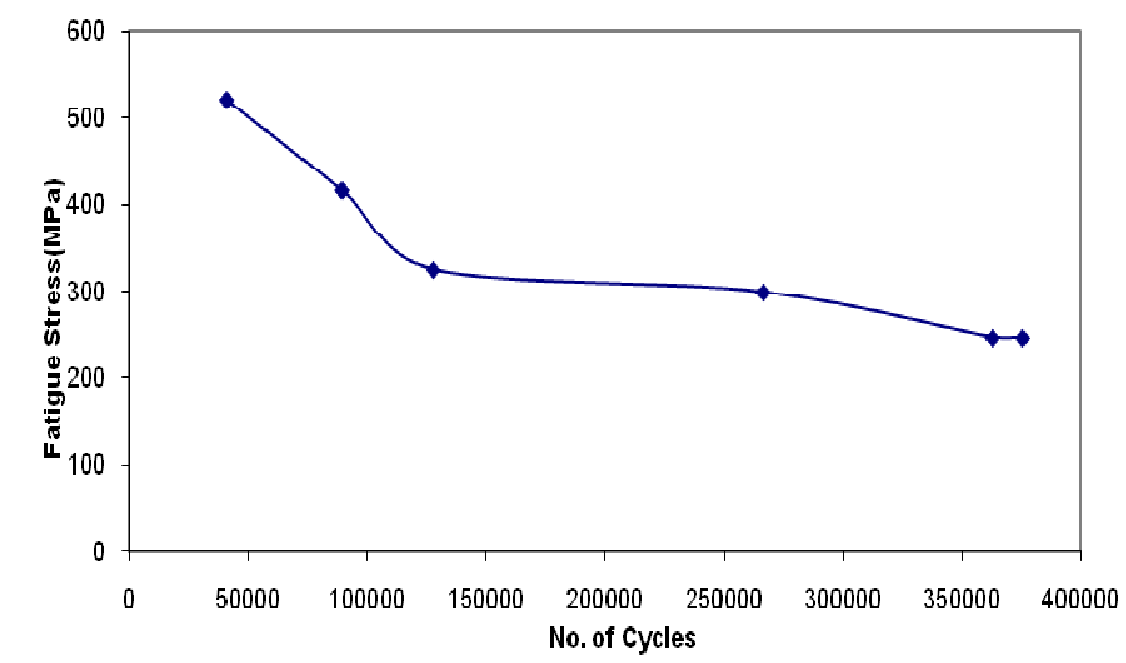

Figure 16. S-N diagram for steel bar heating and cooling by water $\left(\mathrm{C} . \mathrm{R}=77^{\circ} \mathrm{C} / \mathrm{sec}\right)$

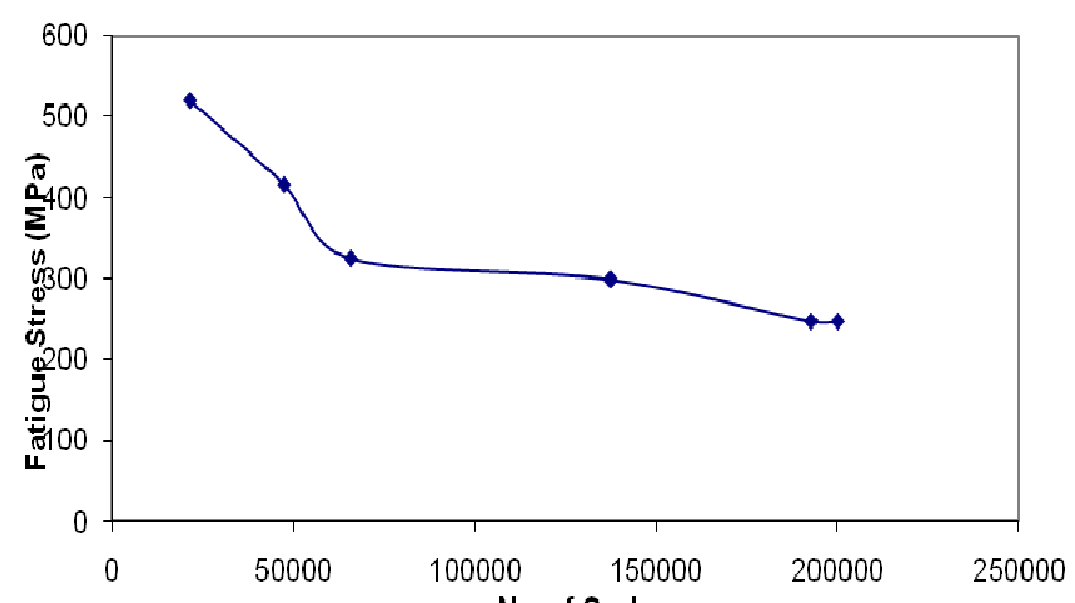

No. of Cycles

Figure 17. S-N diagram for steel bar heating and cooling by brine $\left(\mathrm{C} . \mathrm{R}=150{ }^{\circ} \mathrm{C} / \mathrm{sec}\right)$ 


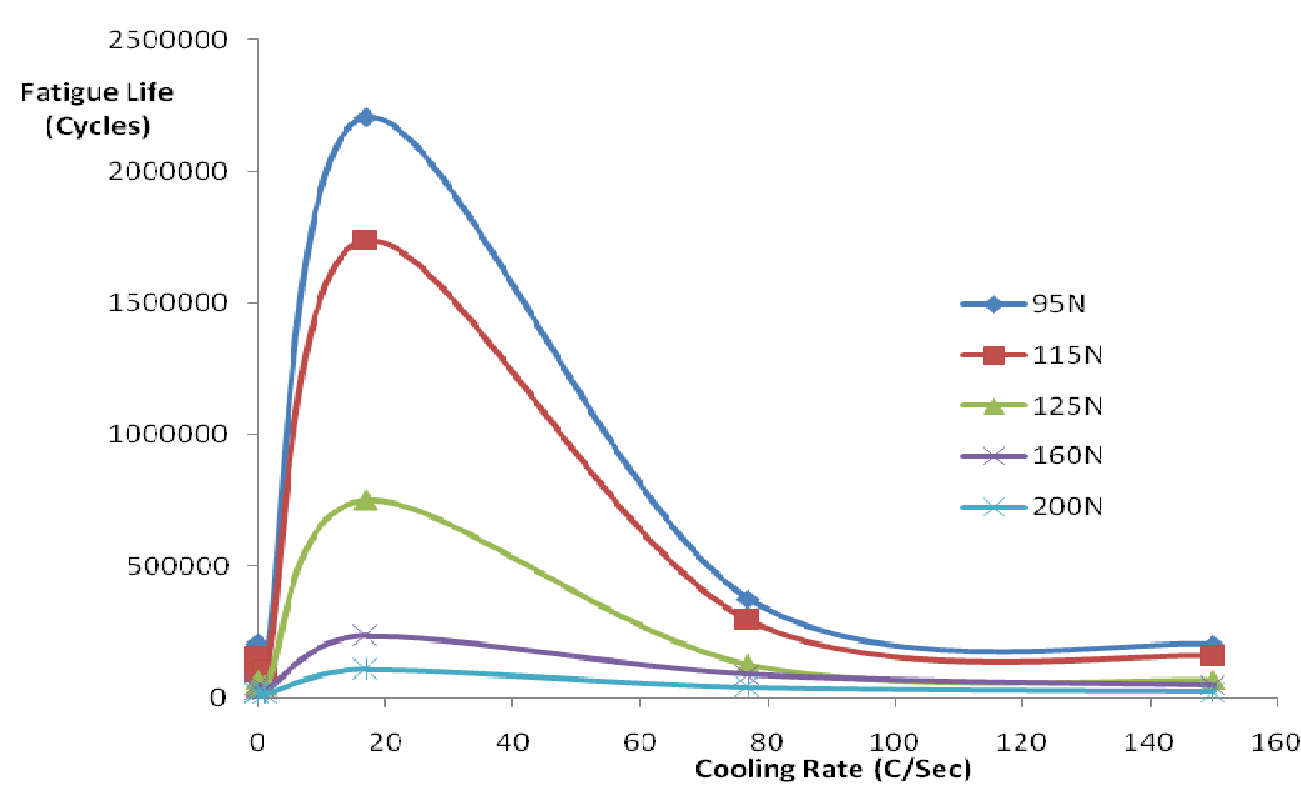

Figure 18. Relation between the cooling rate and fatigue life at different load

\section{Conclusion}

The Fatigue life of steel bar can improved by heating to (930Co) and cooling by oil about (10 times) of it for original state samples (without heating and cooling).

The medium cooling rate (by oil, water) gave best fatigue life than other type of cooling media.

The yield strength of steel bar increased about (17\%) of the original state sample.

The ultimate tensile strength of steel bar increased about (16\%) of the original state sample.

The lower values of fatigue life were for steel bar samples that cooled inside the furnace (very slow cooling rate).

\section{Acknowledgments}

The author would like to acknowledgment mechanical engineering labs in Engineering College/University of $\mathrm{Kufa} / \mathrm{Iraq}$, for support this work.

\section{References}

Andresen, P., \& Antolovich, B. (1997). Fatigue and Fracture. ASM Handbook.

Bathias, C., \& Paris, P. C. (2005). Giga-cycle Fatigue in Mechanical Practice. Marcel Dekker.

Brown, J., \& Sashi, K. K. (2004). Low-cycle fatigue failure of reinforcing steel bars. Materials Journal, 101(6), 457-466.

Bruce, B. (1990). Fatigue Resistance of Steels. ASM Handbook (vol.1, 673-688).

Daniel, H. H. (2007). Oil Quenching. Illinois Institute of Technology, Thermal processing technology center, 2007.

Eren, Y. (2007). Quenching Media during heat treatment. Retrieve from http://turkishengineering.blogspot.com

Fleck , N. A., \& Smith, R. A. (1984). Fatigue life prediction for structural steel under service loading. International Journal of Fatigue, 6(4), 203-210. http://dx.doi.org/10.1016/0142-1123(84)90050-1

Greger, M., \& Kander, L. (2008). Structure and low cycle fatigue of steel AISI 316 after ECAP. Archives of material science and engineering, 31(1), 41-44.

Kharagpour, I. T. (2010). Design for Strength, Stress Concentration (Lesson 2, Version 2).

Lee, Y.-L., \& Pan, J. (2005). Fatigue Testing and Analysis. Elsevier.

Pang. J. C., Li, S. X., \& Wang, Z. G. (2013). General relation between tensile strength and fatigue strength of metallic materials. Materials Science and Engineering A, 564(2013), 331-341. http://dx.doi.org/10.1016/j.msea.2012.11.103. 
Rami, H., \& Adeeb, R. (2010). Low cycle criteria for mild steel bars under combined bending and axial loading. University of Wisconsin-Milwaukee, Dept. of civil engineering and mechanics. 2010.

Tilly, G. P. (1979). Fatigue of steel reinforcement bars in concrete. Fatigue of engineering materials and structures journal, 2, 251-268.

Tohru, A. (1997). Heat Treating. ASM Handbook.

Walter, D. P. (1997). Petersons stress concentration factors (2nd ed.). Wiley. http://dx.doi.org/10.1002/9780470172674 .

Yukitaka, M. (2002). Metal Fatigue: Effect of small defect and nonmetallic inclusions. Elsevier.

\section{Copyrights}

Copyright for this article is retained by the author(s), with first publication rights granted to the journal.

This is an open-access article distributed under the terms and conditions of the Creative Commons Attribution license (http://creativecommons.org/licenses/by/3.0/). 